Investigaciones geográficas, $\mathrm{n}^{\circ} 45$ (2008) pp. 29-61 ISSN: 0213-4691
Instituto Universitario de Geografía Universidad de Alicante

\title{
AVANCE Y REPERCUSIÓN DEL REGADÍO SOSTENIBLE EN LAS ZONAS RURALES DE ALICANTE: RETO Y OPORTUNIDADES
}

\author{
Cipriano Juárez Sánchez-Rubio \\ Departamento de Análisis Geográfico Regional y Geografía Física \\ Universidad de Alicante
}

\section{Objetivos}

Este trabajo tiene como objetivos concretos:

- Conocer y estudiar la situación actual de la agricultura de regadío sostenible y sus déficits (falta de garantía de agua), cómo solucionar esta amenaza constante mediante la mejor gestión y optimización del recurso, la reutilización de las aguas depuradas, la práctica de la desalinización e incluso nuevas aportaciones foráneas (trasvases).

- Recuperar las ventajas comparativas de la agricultura de vanguardia mediante una política de integración debido a la favorable renta de situación respecto a los mercados nacional, comunitario (Unión Europea) y globalizado.

- Evaluar adecuadamente el papel de las inversiones en sistemas de regulación públicos y los de iniciativa privada para uso agrario con base al beneficio económico, social, de fijación de población en el medio rural y ordenación del territorio.

- Analizar los potenciales recursos del espacio regado y la oportunidad de ampliar esta superficie manteniendo un equilibrio entre la conservación del medioambiente y la calidad de los recursos naturales. Un reto y una oportunidad tanto para mejorar la condición económica y social de las áreas rurales como para hacer más habitable el territorio. 


\section{Metodología}

La metodología utilizada en el análisis es lineal. Los principales indicadores utilizados son: evolución de la superficie de regadío, distribución de cultivos, superficie acaparada por los cultivos forzados y al aire libre, producción por unidad de superficie, valor de las producciones, coste, margen neto o beneficio, demanda de agua por sistema de riego, empleo generado y evolución y tendencia del comercio agrícola-hortofrutícola de la provincia. Los datos estadísticos utilizados proceden de los centros oficiales mientras los de coste y beneficio proceden de los agricultores, cooperativas agrícolas y empresas particulares dedicadas a la producción y comercialización de los cultivos más emblemáticos. También, en el estudio de los costes, productividad y beneficios de los cultivos más emblemáticos se toman en consideración los Informes del sector agrario valenciano (2000-2006). Para evitar el sesgo derivado de la fuerte variabilidad del precio de los productos se ha optado por tomar en consideración el valor medio del período 2000-2006.

\section{El modelo de desarrollo de la agricultura productivista: beneficio económico-social e impacto medioambiental}

\subsection{Un aumento significativo de disponibilidad hídrica y de la superficie regada}

Las posibilidades y las condiciones de desarrollo del espacio rural de la provincia de Alicante están siempre vinculadas a la gestión y uso del agua de preferente aprovechamiento agrario. En la relación agua-crecimiento económico comarcal,provincial y regional la regla general admitida por los investigadores es que la disponibilidad de este recurso determina la capacidad de crecimiento. El territorio alicantino ofrece posibilidades y plantea inconvenientes para el uso agrario del suelo. El mayor riesgo (debilidad o amenaza) radica en su escasa precipitación total anual, $426 \mathrm{~mm}$, y su elevada variabilidad interanual y estacional. Factor limitante de la producción agraria que a diferencia de la temperatura se puede corregir. Riesgo natural que condiciona el aprovechamiento agrario del suelo mediante cultivos de secano que realizan su ciclo vegetativo antes de que se inicie la aridez estival (trigo, cebada, etc.), o mediante plantaciones arbóreas (olivos, almendros, algarrobos, etc.) y arbustivas (vid) resistentes a la sequía estival.

Esta agricultura de secano depende más de la oportunidad de las precipitaciones que de la cantidad total anual recibida. El suelo aprovechado por los cultivos obtiene baja productividad, no garantiza la producción y provoca el abandono de la explotación que se hace significativo en los períodos de sequía. En cambio, poder disponer de agua para riego supone convertir un 
riesgo o estrangulamiento en una gran fortaleza productiva al garantizarse las producciones anuales, aumentar los rendimientos por unidad de superficie (fertilizantes) y elevar tanto la productividad de la tierra como su valor. Por ello, las grandes transformaciones territoriales del paisaje agrario (se sustituye el policultivo de secano por cítricos, hortalizas, frutales, flores y plantas ornamentales) y del desarrollo económico local se han fundamentado en el uso y garantía de los recursos de agua. Superficie catalogada de regadío que no recibe la cantidad de agua adecuada, a pesar de la vasta infraestructura hidráulica creada.

La política española en el medio rural se ha definido por dos criterios: el económico-productivo y el político-social. El primero tiene como objetivo el aumento de los rendimientos para abastecer la creciente demanda alimenticia mientras el segundo se centra en la reforma de las estructuras de la propiedad agraria. La solución ofrecida ha sido la ampliación del espacio regado al considerarle como vanguardia de modernización agraria del país. Los territorios beneficiados por las inversiones públicas y privadas han conseguido los objetivos tanto económico y sociales (generación de empleo), como los de fijar población en el medio rural y ordenar el territorio. Esta forma de explotación de la tierra es rentable, competitiva y dinámica como factor básico para el desarrollo rural pero la escasez de agua condiciona su expansión. La corrección por economía del agua se ha realizado mediante las aportaciones vinculadas a la presencia del río Segura, el aprovechamiento de sobrantes; la explotación de las aguas subterráneas, de iniciativa privada; y el trasvase Tajo-Segura, de iniciativa pública.

Los procesos descritos se refieren siempre al uso agrario del agua tratando de promover el desarrollo económico de las diferentes comarcas mediante la ampliación continuada de la superficie de regadío. Por esto, las condiciones naturales no son capaces de explicar totalmente las diferencias en la utilización del suelo agrario. Los factores humanos tienen una importancia tan decisiva como ellas. Las tradiciones históricas, las coyunturas creadas por la economía moderna, la estructura de las explotaciones, el régimen de tenencia, las políticas regionales y los procesos socioeconómicos como el desarrollo industrial, la capacidad de transporte, la accesibilidad, la integración en las vías comerciales, etc., evidencian que el desarrollo agrario alcanzado es el resultado de valorizar la aportación de los recursos locales tanto naturales como humanos del territorio (conjunto formado por la sociedad y el espacio que ella organiza).

La existencia del regadío agrario goza de larga tradición en la comarca del Bajo Segura (fig. 1). Todavía está en pie y uso la infraestructura hidráulica 
creada desde época musulmana. Ésta se caracteriza por el exclusivo uso de los recursos superficiales del río Segura para transformar suelos improductivos en zonas de considerable riqueza. Su sistema de distribución del agua, sobre la base de la costumbre y la proporcionalidad, busca la máxima economía en la utilización del recurso mediante los principales elementos tecnológicos de azudes, acequia, azarbe, noria, etc. La superficie regada se acrecienta con la puesta en funcionamiento de los pantanos de Tibi y Elche en el Vinalopó junto a las acciones realizadas para aumentar la disponibilidad de caudales tanto privados (concesión de caudales sobrantes del río Segura, Canal de la Huerta de Alicante, explotación de aguas subterráneas) como públicos (Plan de aprovechamiento del río Segura, orden del 25 de abril de 1953 y el trasvase Tajo-Segura, ley de 19 de junio de 1971 y ley 52/1980 sobre el Régimen económico). La mayor disponibilidad y garantía de agua permite la expansión del regadío en la provincia que viene motivada por la doble vocación de potenciar la productividad de la tierra, aprovechando el período libre de heladas, y explotar las favorables condiciones de valoración climática fundamentada en la insolación-luminosidad. Estos dos objetivos han dado lugar a agriculturas diferentes de regadío y modelos de desarrollo. Las favorables condiciones térmicas de suavidad invernal y las altas temperaturas estivales junto a la fertilidad de los suelos impulsan la transformación del espacio agrario de secano a regadío mediante la corrección de la escasez de caudales. La metodología aplicada para conocer las necesidades totales de agua de los cultivos se ilustran bajo la fórmula de balances hídricos (Thornthwaite, Blane y Criddle). Éstos comparan la lluvia media mensual con los estimados requerimientos de agua por los cultivos e incorporan coeficientes estacionales de consumo (Blaney y Criddle) en relación con la eficacia del suelo. Un criterio agronómico que permite conocer la diferenciación climática de las comarcas y las necesidades de agua de los cultivos en cada lugar y tiempo para asegurar la producción y la renta del agricultor. Los avances técnicos y científicos de la segunda mitad del siglo xx permiten al agricultor alicantino aprovechar las favorables condiciones naturales y convertir las debilidades (escasez de agua) en una fortaleza productiva ampliando el espacio regado de una manera significativa. Este proceso obliga al agricultor a romper con el marco propio donde había desarrollado su vida y asentado el policultivo de secano. Se supera la clásica situación en que la proximidad geográfica privilegiaba las relaciones de la producción agraria y su comercialización. El medio físico provincial se transforma en un espacio socioeconómico evolucionado mediante la realización de infraestructuras (mejora la capacidad de transporte, la accesibilidad y la 


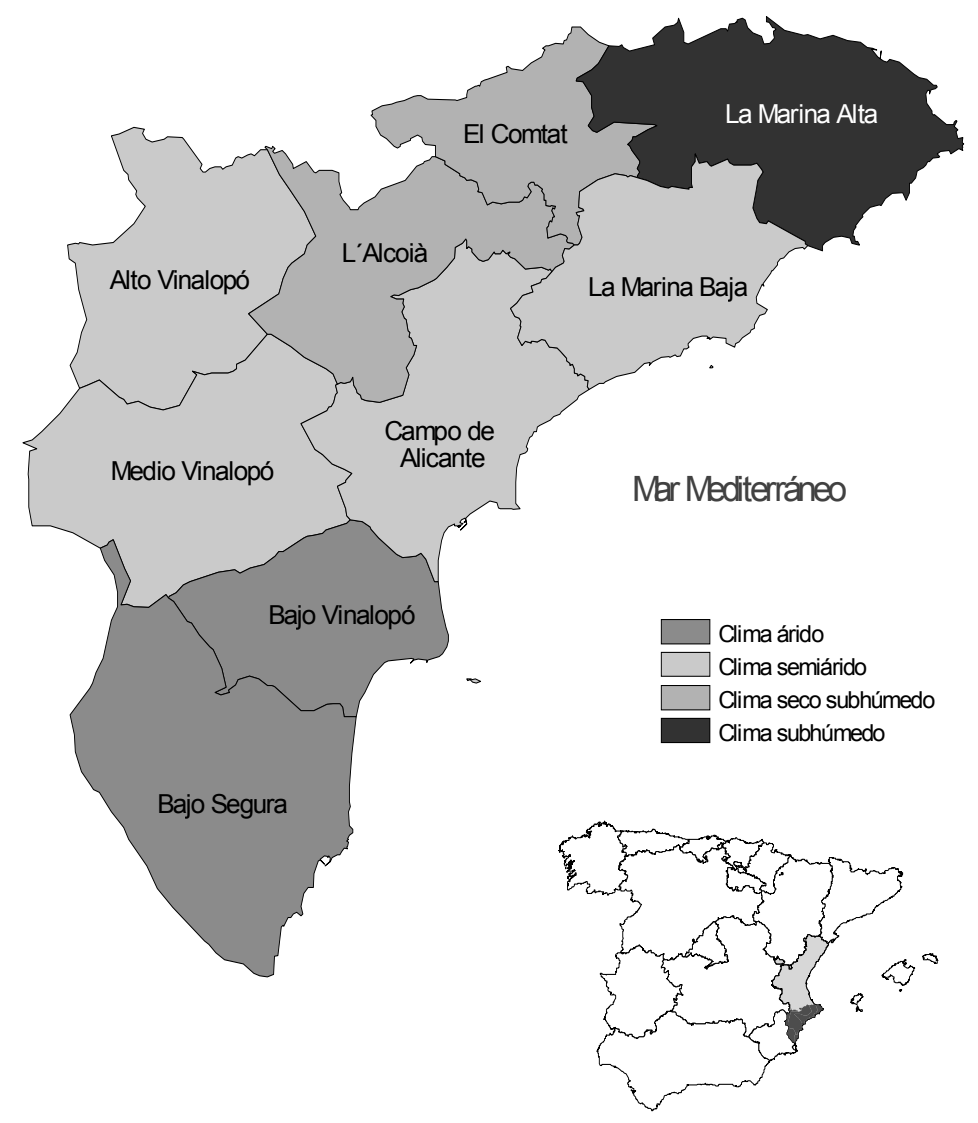

Figura 1. Tipología agroclimática de la provincia de Alicante.

facilidad de comerciar las producciones agrarias) que lo individualiza como medio de producción y le dota de nueva funcionalidad.

El moderno sector agrícola de regadío se liga a nuevos circuitos comerciales extrarregionales. En cambio, el modelo de agricultura tradicional, marginado, determina flujos débiles y relacionados con un área menor de influencia. La riqueza del campo es drenada por las empresas nacionales o internacionales cuyas redes de abastecimiento y distribución al mercado están intercomunicadas. El agricultor alicantino, experto, dinámico y favorecido por su renta de situación es sinónimo de exportador pero condicionado por los procesos endógenos (escasez de agua en relación con su potencialidad productiva) y los exógenos actuales de la Política Agraria Común (PAC), Or- 
ganización Mundial del Comercio (OMC), Directiva Marco del Agua (DMA), las demandas de agua no agrarias (turismo) y la tecnología.

El proceso seguido por la agricultura alicantina, en coherencia con la política española en el medio rural, ha sido la ampliación continuada del espacio regado al ser considerado como vanguardia de modernización agraria del país. Por ello, ha buscado nuevos recursos de agua en su territorio (iniciativa privada) como se ha beneficiado de las obras públicas realizadas por el Estado mediante el Plan de aprovechamiento del río Segura que evalúa las disponibilidades hídricas futuras (aumento de los recursos de agua en un $72 \%$ de los existentes), las asignaciones a las diferentes áreas regables y la superficie objeto de ampliación (3500 ha en el Bajo Segura). Superficie concedida para riego que no guarda relación alguna con las hectáreas solicitadas y transformada por los agricultores ya que éstas fueron de 14089 ha, cuatro veces superior a las contempladas en la orden del 25 de abril de 1953, debido, sin duda, a las favorables condiciones socioeconómicas que el regadío reporta frente al secano.

Esta política de ampliación del espacio de regadío, por encima de las posibilidades de garantía de disponibilidad hídrica y calidad del agua, tiene su confirmación estadística más expresa tanto en la concesión de caudales sobrantes del río Segura a la Compañía de Riegos de Levante(sirve para ampliar la superficie regada en casi $40000 \mathrm{ha}$ ) como en la solicitud de las 14089 ha de la Vega Baja del Segura. Aumento del espacio regado que no ha tenido garantía de disponibilidad y calidad de agua hasta la llegada de los aportes procedentes del trasvase Tajo-Segura en 1979 (redotación). Esta desarmonía entre la superficie regable y los recursos disponibles impulsa la explotación de las aguas subterráneas de iniciativa privada. Alternativa de oferta de agua entre 1960-1980 que es el origen de la agricultura de vanguardia, productiva y rentable. Nueva agricultura conformada sobre la base de pequeñas unidades de producción tecnificada (invernaderos y riego localizado), capitalizada, de flamantes cultivos y de venta al mercado exterior, de preferente localización en el sector litoral.

Sin embargo, las acciones mineras del agua en las comarcas del Bajo Segura y el Bajo Vinalopó provocaron un descenso alarmante en sus acuíferos. En este nuevo escenario el modelo de gestión de la oferta de agua en España ha consistido en tratar de llevar más recursos donde más demanda hubiera. Como los mayores incrementos de demanda de agua se producen en esta área de clima benigno del sureste peninsular (Alicante, Murcia y Almería) se recurre a trasvasar caudales regulados excedentes y procedentes de la cabecera del río Tajo a la ampliada cuenca del Segura (se incluye el Bajo Segura, el Bajo 
Vinalopó y el Campo de Alicante) con criterios de finalismo de las producciones y de rentabilidad económica y social.

La política de riegos contenida en los planes de desarrollo económico tenía como objetivo fundamental conseguir el mayor crecimiento del producto bruto mediante la aplicación del recurso agua en los territorios de mayor potencialidad económica. La planificación hidráulica implicaba, por tanto, una adecuada y responsable distribución de las disponibilidades de agua por los poderes públicos basada en los intereses sociales. Estas razones estrictamente económicas, también políticas, propias del modelo desarrollista y de la situación concreta del sureste peninsular (escasez de agua en relación con las posibilidades productivas) influyeron en la realización del trasvase Tajo-Segura. La ley 52/1980 de 16 de octubre fija el destino de $125 \mathrm{hm}^{3} /$ año para uso agrícola distribuidos en la forma siguiente: $97,5 \mathrm{hm}^{3}$ para Riegos de Levante Margen Izquierda, 5,5 $\mathrm{hm}^{3}$ para Riegos de Levante Margen Derecha, $14,5 \mathrm{hm}^{3}$ para la zona regable de La Pedrera y $7,5 \mathrm{hm}^{3}$ para los Saladares de Alicante. Un volumen de agua que se acrecienta cuando se toma en consideración los 2,78 $\mathrm{hm}^{3}$ asignados a Pilar de la Horadada (Bajo Segura) incluida en el sector del Campo de Cartagena (Murcia). Recursos hídricos foráneos que se aplican a 62219 ha de regadío bajo los términos de superficie atendida exclusivamente por el agua del trasvase, 29628 ha, y el resto de regadío preexistente y mejorado (redotado).

Los procesos descritos están referidos siempre al uso del agua para aprovechamiento agrario tratando de promover el desarrollo económico y social de las diferentes comarcas mediante la ampliación de la superficie de regadío. Esta superficie ha variado de 95266 ha en 1960 a 138122 ha en 1986 . Un aumento del $45 \%$ que supera con creces el 38\% de la Comunidad Valenciana y el $14 \%$ de la media de España. Expansión de la superficie regada que es el resultado del balance producido entre los municipios que avanzan y los que disminuyen por desarrollo urbano-turístico, las infraestructuras viarias (autovías), y el desarrollo industrial. Espacio regado que presenta profundos contrastes internos y diferentes dinámicas tanto en la superficie regada (el Medio Vinalopó transforma 12600 ha de uva de mesa, el 33\% del aumento del regadío provincial) como en el tipo de cultivo dominante y su rentabilidad económica y social. Un ritmo de incremento del regadío que cambia en 1986 hasta alcanzar 110104 ha en el año 2006. 


\subsection{Cambio en la economía agrícola y mejora económico-social del medio} rural: cultivos intensivos e impacto ambiental

La agricultura productiva, rentable, competitiva y dinámica es un factor básico para el desarrollo del mundo rural. El regadío es una potente actividad económica que mediante la producción, comercialización, industrialización y transporte mueve una gran cantidad de mercancías en fresco para atender las demandas del mercado interior, aumentar la exportaciones y mejorar la balanza comercial. También, elevar los rendimientos por unidad de superficie, introducir nuevos cultivos y aprovechar la tierra de forma más intensa, frente al cereal de secano de año y vez. Los beneficios aportados por el riego se materializan en el aumento del valor de la tierra, en la disminución del riesgo de la empresa agrícola y un alza de la productividad. El regadío significaba, en 1955, multiplicar la rentabilidad de la misma superficie de secano entre 10 y 15 veces cuando el suelo transformado se aprovechaba con cítricos, viñedos en espaldera y parral, hortalizas, etc. Mejora económica que beneficia el orden social por el despegue de los gastos, justificado por la mayor cuantía del número de jornales, el incremento de la masa salarial y el mayor crecimiento demográfico.

En el Tratado de la Comunidad Económica Europea, uno de los objetivos de la Política Agrícola Común (PAC) era asegurar los abastecimientos mediante precios razonables para los alimentos. La necesidad de conseguir estos objetivos pasaba por incrementar la producción agrícola. El aumento de la producción se alcanza mediante el incremento de la productividad que se acompaña del mayor uso de fertilizantes, pesticidas y maquinaria agrícola. El regadío alicantino, coherente con la PAC, tiene como objetivo aumentar la producción, ser productivista y de carácter familiar. La demanda de los nuevos productos obtenidos (cítricos, hortalizas, frutales, etc.) ha crecido vertiginosamente como resultado de la elevación del nivel de renta de la población europea y nacional, el aumento demográfico, y la nueva dieta alimenticia. La respuesta del agricultor ha sido la intensificación de la producción agrícola mediante el aumento de alimentos y su variedad. El éxito de la PAC ha generado excedentes y ha propiciado el aumento de la contaminación.

Este proceso de mejora de rentabilidad económica de la explotación agrícola se ha realizado mediante la incorporación de diferentes avances tecnológicos, la mayor utilización de los productos químicos (fertilizantes) y la mecanización. El empresario agrícola asume la idea de que, invirtiendo más, ganaba más. Por ello, la búsqueda del máximo beneficio en la producción le ha llevado a superar con creces la medida de fertilizantes recomendada por unidad de superficie en el ámbito de nuestra comunidad y de los países 
industrializados. Este uso excesivo e inadecuado de fertilizantes y pesticidas ha dado lugar a la contaminación de ambientes agrícolas, al agotamiento de los recursos hídricos, alterar el agua y el suelo por la excesiva concentración de nitratos y fosfatos, erosión y despoblación de las comunidades rurales. En 1990 los datos referidos a la Comunidad Valenciana ponían de manifiesto que cerca de 800000 habitantes consumían agua potable cuyos niveles de concentración de nitratos estaban por encima de los recomendados por la Comunidad Europea. La situación generada era consecuencia del asentamiento de la población en zonas de cultivo de cítricos, cuyas prácticas intensivas de abonado han provocado altos índices de contaminación en el agua.

La quiebra de la agricultura tradicional y la penetración del capitalismo en el sector agrario acaba con el modelo de subsistencia. Se comienza con el uso intensivo de cultivos y fertilizantes para satisfacer la demanda de productos con precios asequibles para la población. La nueva agricultura alicantina adapta sus productos a la demanda del mercado y por ello percibe el dinero que le permite continuar produciendo y conseguir un beneficio económico y alta rentabilidad. Los nuevos métodos aumentan la productividad y los rendimientos al tiempo que convierten la actividad agraria en un sector dependiente de las fluctuaciones del mercado extranjero. Las nuevas condiciones agrícolas han permitido realizar un cambio radical en la agricultura de regadío del territorio alicantino que pocas zonas del resto de España han experimentado. La confirmación estadística de este cambio se realiza con base a la mejora de las estructuras agrarias de carácter familiar, la introducción de nuevos cultivos, el desarrollo intensivo de las hortalizas, la proliferación de los invernaderos, la sustitución del riego tradicional por el localizado o de goteo, el aumento de la productividad, el alza de la renta de los empresarios agrícolas y el empleo generado.

Esta agricultura de vanguardia juega un papel fundamental en el crecimiento económico tanto por su valor como por el efecto multiplicador que genera hacia otros sectores de la economía: productos transformados alimentarios (sector industrial) y los que se manipulan/envasan puestos a disposición del consumidor (sector terciario). Los usos del suelo mediante cultivos están relacionados con el valor total de las producciones, la adecuación a la capacidad del trabajo familiar y una cierta garantía de comercializar las producciones. Un espacio regado caracterizado por el predominio de los cítricos, hortalizas, frutales, flores, plantas ornamentales, etc. Auge del sector hortofrutícola más relacionado con la dialéctica tecnificación-producciónexportación que con los aspectos relativos a la propiedad de la tierra o deficiente estructura de las explotaciones. $\mathrm{Y}$ es que los mayores rendimientos y 
producciones llevan asociado, evidentemente, una mayor mano de obra que el secano correspondiente y la no dependencia de la política de ayudas de FEOGA, garantía establecida por la PAC. Mayor función de trabajo de estos cultivos que varía entre el 10\% de cereales regados por aspersión y un $4000 \%$ en los cultivos de invernadero y bajo plástico.

Sin embargo, en la segunda mitad de los años ochenta del siglo pasado se inicia un proceso de reducción de la superficie de regadío productivo del sector litoral y de la zona interior de la provincia. La fuerte competencia de otras tierras de España y de ciertos países emergentes afecta a algunos de los productos más emblemáticos del territorio alicantino. También la escasez de agua y los elevados costes de producción en relación con los precios percibidos por el agricultor justifican la disminución de la superficie regada aunque no se ha modificado su composición. Estructura productiva que sigue acaparando entre el $75 \%$ y el $80 \%$ del valor de la producción agrícola al ser los productos (hortalizas, cítricos, frutales, flores, etc.) los que ofrecen mayor rentabilidad económica y social.

Las explotaciones de regadío en el ámbito de las zonas rurales de Alicante significan la supervivencia de los cultivos y, por ende, de la población. La falta de caudales de agua (sequías), a pesar de la obra pública del trasvase TajoSegura y los caudales asignados, ha tenido (período1991-1995) gran repercusión económica, social y ecológica en las explotaciones. Se redujo la superficie cultivada en un $20 \%$, la producción en un 52\%, la renta agraria en un $51 \%$ y los puestos de trabajo en un 50\% como daños medioambientales difícil es de evaluar. No obstante, este regadío tiene capacidad para administrar bien los recursos de agua en cantidad y calidad (mayor amenaza de la producción agrícola) como hacer competitiva su producción en calidad y precio, en un mercado cada vez más globalizado, mediante la compatibilidad de los criterios económicos, sociales y medioambientales. Una forma de explotación de la tierra capaz de permanecer en el tiempo (durable) cumpliendo las funciones básicas de ser económicamente viable, socialmente útil y ambientalmente sostenible. Estos problemas generados por la agricultura productivista son los que crean la agricultura sostenible.

El regadío tradicional (anterior a 1933) también ha reducido la superficie regada con pérdida significativa de funcionalidad económica de su agricultura. La Huerta de Alicante, Elche y la Vega Baja se han convertido en un área del espacio rural sometida a la presión del mundo moderno. La capacidad de pago de estos regadíos es baja y no pueden asumir los costes derivados de la disponibilidad de recursos externos que disminuyan la situación estructural de déficit hídrico. Se ha reducido la superficie regada por el proceso 
urbanizador y la escasez y calidad del agua, convirtiéndose en una zona de marginación económica. El agricultor no soporta la permanente situación de crisis de precios y la presión social del sector litoral y opta por vender el suelo agrario para modernas urbanizaciones, complejos residenciales, expansión de los servicios, infraestructuras viarias (autovías, autopistas, nuevas carreteras, AVE, etc.) y las expectativas de crecimiento urbano. Una superficie productiva que cambia el uso del suelo debido al desajuste existente entre el precio de los inputs pagados por el agricultor (salarios, abonos, agua, fitosanitarios, etc.) y el precio pagado por los productos.

Se ha pasado de una situación boyante en la zona de huerta y vegas, ocupadas por el regadío tradicional y productoras de cítricos y hortalizas, a cuestionar su viabilidad económica. Estas explotaciones que fueron consideradas como alternativa a la crisis de la agricultura tradicional de los años cincuenta del siglo pasado, debaten su aptitud económica, desde 1986 a la actualidad, por merma de su rentabilidad. Este regadío tradicional está reduciendo su espacio productivo por la baja calidad de las aguas del río Segura (tiene una cantidad de sal que oscila entre 2,3 y 3,7 gramos/litro y que motiva pérdidas continuadas en la producción entre un $25 \%$ y un $40 \%$, que llega a ser del $60 \%$ en los períodos de sequía), y la disminución de los caudales concedidos después de la entrada en funcionamiento de los embalses reguladores. Sin embargo, se puede y debe mejorar la competitividad de esta agricultura ya que si uno de los objetivos del mundo rural es su desarrollo económico, no podemos pretender quedarnos solamente con la agricultura de vanguardia y exportadora mantenida por los caudales procedentes de la cabecera del río Tajo. Sería renunciar a una actividad fundamental de la economía rural, el equilibrio social y territorial y la protección del medioambiente.

\subsubsection{Potencialidad hortofrutícola, vocación exportadora e impacto del marco internacional de intercambios}

El modelo de desarrollo agrario del sector litoral se conforma sobre la base de la potencialidad hortofrutícola y la vocación exportadora. En este espacio productivo (Bajo Segura, Bajo Vinalopó y Campo de Alicante, también L'Alacantí) se concentra la agricultura de vanguardia, caracterizada por su alta capacidad de innovación técnica, la elevada rentabilidad y la venta de las producciones en fresco al mercado nacional y de la Unión Europea (el 87\% de la exportación agrícola). Su capacidad productiva se acrecienta cuando se toma en consideración que muchos de sus productos se recolectan en el momento de mayor interés económico (invierno). Su práctica permite una mayor flexibilidad a la oferta agraria tanto por su menor dependencia de la climatología 
como por la variedad de productos. Agricultura rentable y dinámica que pasa por ser la más importante del espacio rural de la provincia.

El regadío de cultivos forzados (invernadero, acolchados, enarenados, túneles, calefacción, etc.) es una forma de producción de la tierra compatible con la PAC y las tendencias globalizadoras de la OMC. La variable natural que mejor explica la viabilidad económica del regadío intensivo del sector litoral alicantino son las favorables condiciones térmicas, la valoración climática fundamentada en la insolación-luminosidad, el número de horas de sol, la radiación solar y la pequeña propensión de heladas. En tal sentido, la suavidad térmica del invierno (el mes más frío registra temperaturas superiores a $11^{\circ}$ ) apoyada por el resto de los elementos mencionados identifican al sector litoral como el espacio mejor dotado para el aprovechamiento del suelo, al aire libre o bajo cubierta, por hortalizas, flores y plantas ornamentales poco propensas a soportar heladas. Cultivos intensivos que aumentan sus rendimientos de forma considerable al confirmarse que un metro cuadrado a cielo abierto produce cinco kilos de tomates por temporada mientras esta misma superficie cubierto con una instalación primitiva (a base de plástico) suele llegar hasta 15 kilos. Un margen de mejora todavía más amplio cuando los invernaderos incorporan las últimas tecnologías capaces de producir entre 25 y 50 kilos por metro cuadrado.

El período libre de heladas aumenta en función de la menor altitud y proximidad al mar. El Inventario agronómico de cítricos de 1991 indica que el riesgo de heladas de estos cultivos era del 89\% en Alicante, donde tal posibilidad subía al 93\% en el caso del limonero, especie más sensible al frío, que está prácticamente libre de tal peligro por su localización en el extremo meridional de la provincia. Sin embargo, estos mínimos térmicos que no llegan a fuertes descensos, sí pueden causar daños en ciertos cultivos hortícolas (alcachofas), frutales y los indicados cítricos (enero-febrero de 1985, diciembre 1994, abril de 1999 y enero de 2005) que en las comarcas meridionales suelen florecer a principio de febrero cuando el período libre de heladas no está totalmente vencido. Un factor de incidencia agraria que provoca irregularidad productiva difícil de corregir frente a la posibilidad de paliar la falta de agua (sequías).

La casi totalidad de la superficie de la agricultura de vanguardia, el $90 \%$, está ocupada por los tres cultivos más emblemáticos: $53 \%$ cítricos, $23 \%$ de hortalizas y $14 \%$ de frutales. Los cítricos, dominados por el limonero y sus favorables condiciones de adaptabilidad a los suelos calizos, su poca apetencia por el agua, la escasa mano de obra y su precio cambiante, han variado su distribución al pasar a ser mayoritariamente de naranjos de mayor precio del producto y más fácil comercialización. Además, la producción de naranjas 
nunca ha tenido un reparto varietal mejor. Nueva situación productiva que permite al sector competir con el resto de los países productores en mejores condiciones. Una forma de aprovechamiento de la tierra que sigue siendo socialmente rentable (genera 75 empleos por $\mathrm{hm}^{3}$ ), económicamente básica, y productivamente mejorable ya que las explotaciones agrícolas están dominadas por el minifundio (el 90\% tiene una superficie menor de 5 ha), que dificulta su modernización para reducir costos. Un tipo de agricultura factible necesitada de que el beneficiario sea quien trabaje la tierra, reduciendo los abusivos márgenes de distribución y comercialización. Su contribución al valor total de la producción agrícola es de $40 \%$.

La superficie ocupada por las hortalizas acapara el 23\% de la superficie productiva de vanguardia, contribuye con el $50 \%$ del valor de la producción agrícola y genera un empleo de 250 jornales por $\mathrm{hm}^{3}$. Su productividad se mejora mediante las incorporaciones tecnológicas más avanzadas ya que los mercados están garantizados por su gran calidad. El aprovechamiento del suelo o la sustitución por cultivos hidropónicos (sin suelo) se realiza mediante: tomate, pimiento, alcachofa, lechuga, apio, bróculi, flores, plantas ornamentales, etc. Explotaciones familiares atendidas por los caudales procedentes del trasvase Tajo-Segura que están sometidas a una amenaza constante por la irregularidad de las precipitaciones en la cabecera de aquel colector. Esta debilidad estructural necesita de una solución definitiva ya que la falta de garantía de agua provoca incertidumbre en la agricultura de vanguardia y exportadora cuyo objetivo y estrategia debe ser la consolidación de la superficie regada.

El cultivo de frutales acapara el 14\% y contribuye con el 10\% a la producción agrícola. La expansión del almendro en regadío ha sido tan grande que se ha establecido como monocultivo en el Campo de Elche por la escasa demanda de mano de obra y la buena adaptación a una agricultura a tiempo parcial motivada por el empleo industrial, el desarrollo turístico y la expansión de los servicios. Espacio productivo que se acrecienta con el cultivo del granado y su buena rentabilidad económica como la explotación de la uva de mesa fuera de su ámbito de localización. La mano obra es de 150 empleos por $\mathrm{hm}^{3}$ utilizado.

En cambio, el regadío del sector del interior (espacio no en contacto con el mar) se identifica como un apoyo básico imprescindible de rentabilidad en la actividad agrícola ya que los cultivos que aprovechan el suelo están condicionados por el clima, el capital y las necesidades humanas. En gran proporción, estos cultivos han sido los mismos que en secano porque el agricultor aseguraba una parte de la cosecha de los productos comercializados y transformables en metálico. Los frutales (manzano, peral, cerezo, ciruelo) 
y las hortalizas (zanahoria, puerro, tomate, guisante, etc.) acaparan hasta el $45 \%$ de la superficie de regadío.

Este regadío hortofrutícola del interior de la provincia es el que mayor rentabilidad económica y social ofrece al empresario agrícola de esta zona rural. La transformación de estos campos se ha realizado mediante el aprovechamiento de las aguas subterráneas de iniciativa privada como la mejor forma de elevar la rentabilidad de las explotaciones agrarias y asegurar las cosechas. La superficie productiva se asienta y amplía debido al avance tecnológico y varietal que prolonga las campañas de producción durante el verano. Un área que soporta la menor presión turística inmobiliaria del litoral pero que se está viendo afectada por la escasez de agua, su baja calidad, y el precio pagado por el agricultor frente al recibido por el producto. Se ha introducido el riego por goteo pero el abandono persiste por éxodo rural, y envejecimiento de la población.

En el sector central del Medio Vinalopó el cultivo de la uva de mesa en regadío y la práctica del embolsado para protegerla y retrasar la maduración junto a su favorable comercialización (Denominación de Origen) es una forma de explotación de la tierra rentable pero sometida a las fluctuaciones de los mercados nacional e internacional. La considerable rentabilidad económica y el hecho de que sea un cultivo eminentemente social justifican la proliferación de las explotaciones de pequeña dimensión. Sin embargo, la rentabilidad ha descendido por el precio del agua, abonos, fitosanitarios y mano de obra en relación con los precios percibidos por el agricultor. Un proceso cuantificado mediante el abandono progresivo de la superficie cultivada que tiene su confirmación estadística en la reducción del espacio labrantío que pasa de 15000 ha en 1993 a 8493 ha en el 2005.

La Política Agrícola Común (PAC) es competencia exclusiva de la Unión Europea. El ingreso de España en el concierto de la Unión Europea repercute en la dinámica de la agricultura alicantina por los cambios en la PAC y la OMC. En esta nueva situación el regadío alicantino ha dejado de ser elemento fundamental para el fomento de la riqueza aunque sigue siendo de gran interés para mantener y mejorar la producción agraria. La agricultura de la provincia de Alicante ha perdido significación económica al pasar de contribuir el 8\% del PIB y el 15\% de la población activa en 1976, al 2\% y 3\%, respectivamente, en el 2006. Sin embargo este sector productivo ejerce un papel fundamental en la cohesión social mientras mantiene su competitividad en el subsector de frutas, hortalizas, flores, etc., sin ayudas de la PAC.

El regadío alicantino empezó a incorporar las técnicas agrícolas más avanzadas, invernadero y el sistema de riego localizado de mayor eficiencia (reduce 
la cantidad de agua y mantiene la productividad agrícola), consiguiendo mayor rentabilidad económica y generación de empleo. El mayor reto de los agricultores es poder contar con los recursos hídricos necesarios en cantidad y calidad para garantizar la producción en las mejores condiciones de venta en el mercado. También, contemplar la posibilidad de aumentar la superficie de regadío en relación a las favorables condiciones del producto en los nuevos mercados emergentes.

El riego localizado se empieza a introducir en el campo alicantino a finales de la década de los años setenta. En 1982 la superficie dominada por este sistema sólo afectaba a 1125 ha. La introducción y paralela repercusión económica en las explotaciones agrarias de cítricos, uva de mesa y tomate se confirma, desde mediados de los años ochenta del siglo pasado, al comprobarse la diferencial productiva de la estructura de costo de producción entre las explotaciones regadas por el sistema de inundación (tradicional) y el nuevo sistema de riego localizado. La sustitución del riego tradicional por el moderno de goteo tiene como objetivo elevar la rentabilidad de las explotaciones mediante la reducción del gasto (se consume menos agua y se produce la misma cantidad de producto) y el aumento de los ingresos derivado de la mayor calidad de la producción y aceptación en el mercado.

En el caso del limón, el rendimiento agronómico variaba de $25000 \mathrm{~kg} /$ ha en riego por inundación a $34000 \mathrm{~kg} / \mathrm{ha}$ en riego por goteo. La mayor eficiencia del agua se confirma en la reducción de costo al pasar de acaparar el $20 \%$ al $15 \%$ en riego por goteo. La rentabilidad del cultivo varía de 216000 pesetas en riego por inundación a 470000 en riego por goteo. Este nivel de rentabilidad se mejora, al inicio de los años noventa, mediante el alza del precio de los cítricos (50 ptas./kg), la mayor producción por superficie cultivada (40000 kg) y la reducción del coste del agua a sólo el 12\% de la producción final agrícola. Esta diferencial productiva también se confirma en las explotaciones de uva de mesa del Medio Vinalopó: el rendimiento agronómico en riego por inundaciones era de $17000 \mathrm{~kg} / \mathrm{ha}$ frente a los $21000 \mathrm{~kg}$ del riego localizado. El valor del agua en riego tradicional es del 10\% mientras en el sistema de goteo se reduce al 5\%. La diferencial productiva varía de 2103 euros a 2705. Alta rentabilidad que persiste en 1995 al confirmarse los ingresos netos por ha, respectivamente, de 2174 y 3856 euros.

La incorporación de las técnicas más avanzadas (invernadero y riego localizado) tiene en las explotaciones de cultivo intensivo de tomate la mayor significación de la diferencial productiva. En ambos sistemas de riego los rendimientos agronómicos son muy elevados, $150000 \mathrm{~kg} / \mathrm{ha}$ y $165000 \mathrm{~kg}$, respectivamente. El costo del agua, pasa del $5 \%$ en el sistema tradicional al 
$3 \%$ en goteo. Este mayor ahorro por eficiencia del sistema junto a la mayor producción (un 10\%) explica su mayor diferencial productiva (500000 de las antiguas pesetas) que podía ser mayor en función del mercado (posibilidad de adelantar o retrasar la producción en función de los precios).

En consecuencia, el regadío alicantino era económicamente rentable, antes del ingreso de España en la Unión Europea en 1986, por su gran aportación a la producción final y socialmente por el empleo que generaba. Sin embargo, la difusión del modelo agrario productivista, fundamentado en la intensificación de los cultivos, ha originado problemas a las comunidades rurales materializados en el agotamiento de los recursos hídricos de los acuíferos (sobreexplotación), contaminación por nitratos, alteración de la calidad del agua y los suelos, erosión, etc. Un sistema de práctica agrícola que tenía como objetivo una mayor producción sin tomar en consideración la afectación medioambiental (contaminación). Nuevos problemas que preocuparon a la UE tanto por los excedentes agrícolas como por la contaminación. Incompatibilidades que han sido superadas mediante la sustitución del modelo agrario productivista por otro económico de naturaleza sostenible. Por ello, la agricultura alicantina se adecua a las nuevos marcos legales y actúa sobre el espacio transformado por el riego para convertirse en agricultura sostenible.

\section{Avance y repercusión del regadío sostenible en el desarrollo de las zonas rurales}

\subsection{Necesidad del regadío en una agricultura sostenible}

El desarrollo sostenible se introdujo como objetivo explícito de la Unión Europea en el Acta Única de 1987. El tratado de Mastrique de 1992 obliga a integrar las cuestiones medioambientales en todas las políticas comunitarias. La agricultura de regadío de las zonas rurales de Alicante debe adaptar su modelo productivo agrario hacia el nuevo marco donde priman la reducción de los coste unitarios, la mejora de la calidad de los productos obtenidos, conservar y mantener los recursos naturales y dar solución al dilema de una política agrícola encaminada a aumentar la producción y la política medioambiental de no contaminar con repercusión positiva en los sectores económico y ecológico. El regadío actual y de futuro debe ser capaz de administrar bien los recursos de agua y obtener un producto agrícola competitivo en calidad y precio, en un mercado cada vez más globalizado, mediante la compatibilidad de los criterios económicos, sociales y medioambientales. El nuevo paradigma económico contempla una forma de regadío productivo capaz de permanecer 
indefinidamente (durable) en el tiempo cumpliendo las funciones básicas de ser económicamente viable, socialmente útil y ambientalmente sostenible.

Los objetivos del regadío han evolucionado significativamente, desde los primeros años de la década de los años noventa, al cambiarse su tradicional finalidad de intensificación de la producción agrícola para suministrar alimentos hacia otras funciones más diversas como gestor de los recursos naturales y como factor de equilibrio territorial y desarrollo demográfico. La necesidad de adaptar el modelo tradicional de agricultura exclusivamente productivista al nuevo paradigma más respetuoso con el medio natural comporta no producir menos sino que sus costos sean menores y menos agresivos con las condiciones ambientales. Es decir, la agricultura sostenible comporta tanto continuar incrementando la producción de alimentos para satisfacer las necesidades de la población como mantener la competitividad en precios, cumplir con la calidad exigida por el comercio nacional e internacional y conservar o mejorar los recursos naturales (agua y suelo), necesarios para la producción. Un nuevo enfoque que obliga a abandonar el carácter emblemático que históricamente ha tenido el regadío como motor de desarrollo para significar que la agricultura sostenible tiene que competir con otros usos del agua. También, hacer compatible los principios evolutivos de la PAC con las tres dimensiones (económica, social y ambiental) que caracterizan al denominado regadío sostenible.

El regadío alicantino ha mostrado su gran capacidad de adaptación a las nuevas tecnologías. La superficie de riego localizado afecta a casi 80000 ha y se está haciendo un gran esfuerzo por parte de las diferentes comunidades de regantes, la Administración del Estado y la propia Comunidad Autónoma para conseguir que todo el espacio regado tenga incorporado el nuevo sistema de goteo en el bienio 2010-2011. Sin embargo, la actividad productiva agraria se encuentra inmersa en un proceso de crisis estructural motivado por el desajuste entre los costos de producción frente a la evolución de los precios de venta de los productos obtenidos. El futuro se presenta inseguro e incierto. Por esto, es necesario realizar un diagnóstico de la agricultura y fijar los objetivos a conseguir sobre la doble finalidad de ayudar a impulsar su actividad productiva y posibilitar las mejoras de las condiciones de trabajo, producción y renta de los agricultores mediante la incentivación del empleo, debido el elevado grado de envejecimiento de la población.

El diagnóstico se asienta sobre la base de: 1) La política de precios y mercados ha estimulado la ampliación de la superficie de regadío y la producción hortofrutícola ya que la UE es importadora del $60 \%$ del consumo de frutas y verduras; 2) Las sucesivas alternativas de disponibilidad hídrica y calidad de 
las agua han creado dos tipos de agricultura de características sumamente contrastadas y compartimentos diferentes de cara a la competitividad de las explotaciones de regadío; 3) Predominio de las explotaciones de tipo familiar 4) Estimulación de las técnicas intensivas (invernaderos); 5) Diferencias internas en el grado de comercialización; y 6) Desigual respuesta territorial en relación con el desarrollo turístico y residencial.

Con base al diagnóstico realizado es necesario proponer los objetivos a alcanzar: 1) Tratar de mantener y elevar la competitividad de la agricultura sostenible en función de sus características socioeconómicas en el marco de la PAC y los acuerdos de la OMC como referencia a cualquier estrategia territorial; 2) Sustituir el modelo de abastecimiento de la agricultura de regadío por otro que garantice la disponibilidad de los caudales necesarios, en su lugar y tiempo, para estabilizar el espacio regado e incluso aumentar la superficie dedicada a hortalizas, frutales, flores y plantas decorativas y jardinería; 3) Aumentar el tamaño de las explotaciones agrarias familiares (sinónimo de horticultura intensiva del litoral) para mejorar la rentabilidad económica y la generación de empleo; 4) Producir lo que demanda el mercado; 5) Respeto al medio ambiente y mejora de la calidad productiva; 6) Desarrollar la función distribuidora (comercio) mediante la palanca de la mejora de las infraestructuras por generar valores añadidos; 7) Arbitrar fórmulas que permitan la coexistencia de la agricultura del litoral con el desarrollo turístico y residencial; y 8) Fomentar el capital humano mediante la incorporación de población joven (relevo generacional). Se trata de convertir las debilidades productivas (reto) en fortalezas u oportunidades mediante la garantía y calidad del agua para el espacio regado, superar la competencia con otros usos alternativos (turismo) y conocer la política de los intercambios comerciales (PAC y OMC). Es la mejor forma de recuperar el potencial agrícola y las ventajas comparativas de la agricultura de regadío, en el mercado globalizado y cambiante, con menos restricciones a la hora de cultivar frente a la inseguridad e incertidumbre que actualmente pesan sobre ella.

La repercusión de la PAC en las zonas rurales de Alicante es la consolidación de una agricultura dual: la hortofrutícola poco o nada subvencionada y la extensiva de productos poco competitivos (cereales) casi totalmente protegidos. La agricultura sostenible hortofrutícola está desfavorecida frente a los cultivos económicamente menos viables. Dentro de la PAC se han ido desarrollando diversas reformas desde su inicio como modificados los objetivos por los cambios producidos en la agricultura. La nueva reforma de la PAC de 2003 (integra la política sectorial agraria y la política de desarrollo rural) ha reactivado los precios de la tierra que tiene su mayor subida en las superficies 
para cultivos con menor extensión y sin ayudas directas como la horticultura protegida, los cítricos, frutales, etc. Es decir, el precio de la tierra está ligado a las producciones y precios de los productos acaparando las subidas más altas el regadío que produce lo que se vende. Pero esta política de la PAC empieza a estar cuestionada por la escasez de alimentos y se prepara una nueva reforma, contemplada para el año 2010, con el mercado como protagonista y las menores restricciones a la hora de cultivar. Las favorables condiciones objetivas y ventajosas de clima y renta de situación, condicionadas por la falta de garantía de agua, convierten al medio rural alicantino en un espacio dotado de posibilidades de aprovechamiento agrario del suelo por la nueva agricultura sostenible.

La superficie de regadío de las comarcas de Alicante ha disminuido considerablemente entre 1986 y 2006. Se ha pasado de 138122 ha en la primera fecha a 110104 ha, en el año 2006. Sin embargo, el índice de regadío (superficie de regadío por 100/superficie cultivada) ha crecido significativamente entre 1993 y 2006 en las comarcas en que tradicionalmente el espacio regado ha ocupado mayor extensión. En el territorio dominado por el clima árido (Bajo Segura y Bajo Vinalopó) estos valores han pasado del 80\% y $92 \%$ al $86 \%$ y 95\%, respectivamente. En la zona de clima semiárido (LAlacantí, La Marina Baja, y el Alto y Medio Vinalopó) estos porcentajes están generalmente, entre el intervalo del 40 y 50 \%de la superficie cultivada, excepto en el Alto Vinalopó que sólo acapara el 33\% (ha pasado del 21 al 33\%) y L'Alacantí que se eleva al $52 \%$. Estos valores explican que la superficie de regadío de la unidad territorial climática alcanzara las 123936 ha (90\% del total provincial) en 1986 y sea de 97550 ha (el 89\%) en el 2006. Y es que este territorio reúne una serie de condiciones ventajosas para mantener y poder aumentar la función de producción agrícola del regadío sostenible mediante la reducción de los costes unitarios y la mejora de la calidad de los productos obtenidos.

En cambio, tiene la mayor amenaza de su economía en la falta de garantía en cantidad y calidad del agua para asegurar las producciones, la competencia con otros usos del suelo, más productivos (turismo), las implicaciones derivadas del desarrollo de otras zonas hortofrutícolas españolas y africanas, la concentración de la demanda, y la desarmonía entre los costes de producción y los precios percibidos por el agricultor. La conversión de estas debilidades o amenazas (reto) en oportunidades le permitirá recuperar su tradicional potencia productiva como sus ventajas comparativas ya que es una gran generadora de actividad económica y muy demandante de mano de obra e inputs y servicios procedente de otros sectores. 
La nueva ley de Desarrollo sostenible del Medio rural menciona expresamente el apoyo a la agricultura como una de las acciones necesarias para el desarrollo rural. Sólo el desarrollo sostenible garantiza el futuro del medio rural. Es decir, éste debe basarse en la actividad agraria aunque no exclusivamente. El regadío es un instrumento dinamizador para la transformación socioeconómica de las zonas rurales. Su papel como factor de desarrollo se basa en la productividad de las explotaciones, la renta generada, su competitividad, la reducción de la incertidumbre (frente al secano), en su gran capacidad para integrarse con otros sectores (industrial) y sus efectos demográficos (crecimiento positivo de la población y su fijación en el medio rural). Este papel de la agricultura de regadío como factor de desarrollo no es nuevo. Las grandes transformaciones que se han llevado a cabo desde 1950 a la actualidad han sido impulsadas por la iniciativa pública (las considera vanguardia de modernización agraria) y la privada con base al beneficio económico y social.

El desarrollo del mundo rural pasa por cultivar una parte de su espacio productivo agrario para no depender de las importaciones de alimentos mientras mejora su competitividad en el mercado globalizado. Sin embargo, sin agua no hay agricultura. La sociedad debe saber que para producir hortalizas, frutas, etc., se necesitan entre 4000 y $6000 \mathrm{~m}^{3} / \mathrm{ha} /$ año de lluvia o de riego. Pero la sociedad urbana desconoce, por lo general, el papel productivo del agua en la agricultura, en el equilibrio territorial y en el asentamiento de la población. En el territorio alicantino, de condiciones físico-ecológicas tan favorables, una hectárea de regadío produce entre 10 y 15 veces más que la misma superficie de secano (la media de España es sólo seis veces) y genera una renta entre seis y siete veces superior (la media de España es sólo de cuatro veces). Como el regadío alicantino es una oportunidad para el desarrollo rural de sus diferentes zonas éste debe de ser sostenible y estable. La sostenibilidad debe contemplar al agua como factor de producción y combinar los diferentes recursos para que su utilidad sea máxima y perdurable a lo largo del tiempo.

Las explotaciones de regadío no han modificado la estructura de sus cultivos (cítricos, hortalizas, frutales, flores, etc.), porque son los productos que ofrecen mayor rentabilidad económica y social. La base fundamental de la economía rural de la provincia procede del aprovechamiento agrícola al confirmarse que la producción final agrícola contribuye con el 87\% frente al 11\% de la ganadería. Sin embargo, el peso de la agricultura en la economía ha descendido significativamente tanto a escala nacional como de la Comunidad Valencia y de la provincia de Alicante. En ésta, el indicador de la tasa de población activa pone de manifiesto que en 1976 era del 15,5\% (61 4000 trabajadores dedicados a la agricultura) pasando al 3\% en el 2006 (23700 
trabajadores) mientras el PIB ha variado del $8 \%$ al $2 \%$, en el mismo período de tiempo, respectivamente. Pero la producción con una población agrícola reducida cinco veces y una menor superficie de regadío útil mantiene sus niveles de importancia y consideración económica en la producción y exportaciones. Un progreso innegable que se corresponde con el viejo problema de la falta de garantía de agua en cantidad y calidad debido a las sequías que soportan las diferentes cuencas hidrográficas suministradoras (Tajo y Segura) para garantizar las producciones agrícolas.

\subsection{Plasmación de la agricultura sostenible en el regadío y en el desarrollo rural alicantino}

La agricultura sigue siendo una actividad productiva clave en el desarrollo económico de las zonas rurales y la mayor consumidora de agua (el 65\% del total de la provincia). La transformación que se realiza en las zonas regables tiene como objetivo cambiar el modelo tradicional agrario por el nuevo paradigma económico de la agricultura sostenible mediante la búsqueda de la mayor eficiencia en la utilización del agua y la serie de acciones derivadas de este proceso. Este nuevo modelo de agricultura se fundamenta en los principios de competitividad (menor coste de utilización del agua) y la mínima agresión medioambiental. Se trata de encarar el futuro y la incertidumbre que le rodea (falta de garantía de agua en cantidad y calidad para asegurar las producciones agrícolas) de forma pragmática para solucionar definitivamente el problema de la agricultura más productiva, competitiva y dinámica de la provincia que pierde interés progresivo por la falta de agua. Sin embargo, este regadío actual y de futuro es capaz de administrar bien los recursos de agua actuales concedidos y los no convencionales (depuración, desalación) para obtener una producción agrícola competitiva en cantidad, calidad y precio, en un mercado cada vez más globalizado.

La población rural no es la única afectada por dejar de obtener beneficios ponderados. La posibilidad de indemnizar a los regantes por dejar de regar y producir alimentos no es adecuada por el efecto multiplicador de la economía. Los agricultores no serían los únicos afectados por dejar de obtener unos beneficios ponderados y hacer más habitable el territorio. Otros sectores de la producción agraria también están afectados (empresas de servicios, de venta y aplicación de abonos, fitosanitarios, semillas, viveros, transporte, fabricación de zumos, maquinaria, etc.). Las pérdidas en estos sectores económicos es cuatro o cinco veces superior a la cuantía de los agricultores perjudicando a las zonas rurales y a su población (acelera el desequilibrio demográfico). Por 
ello, es necesario y de obligado cumplimiento modernizar el regadío y hacerlo más eficiente en el uso del agua.

La escasez de agua tiene que dejar de ser un problema. La dependencia del agua no debe condicionar el futuro de nuestras generaciones. El Estado debe conciliar intereses contrapuestos y tomar decisiones para resolver el problema. La gestión del agua tiene que ser un ejercicio sinpar de solidaridad (se pide porque existe un desequilibrio)entre cuencas hidrográficas y unidades territoriales. Los conflictos por el aprovechamiento del agua deben ser resueltos por el Estado. Éste debe armonizar intereses adversos y tomar decisiones para solucionar estos y otros problemas.

Los avances científicos y tecnológicos producidos desde los años sesenta del siglo pasado permiten resolver los conflictos hídricos mediante la regeneración de las aguas urbanas e industriales (produce agua de mejor calidad), la desalación de las aguas salobres y salinas, la eficiencia en la red de distribución, la implantación y desarrollo del riego localizado, la mayor facilidad de disponer de agua subterránea a bajo coste, etc. La producción de agua por estas mejoras técnicas ha permitido que el territorio alicantino no haya padecido restricciones, por lo general, para abastecimiento urbano e industrial (está conectado a la red) pero existe una permanente, continuada y radical restricción en el sector agrario. Por tanto, es de obligada justicia social garantizar a los agricultores los necesarios recursos de agua que permitan el desarrollo sostenible (mejora de la eficiencia) del espacio regado. Lo contrario sería caer en la irracionalidad económica y social más completa ya que el regadío alicantino necesita más garantía de agua que disponer de tierra. La disponibilidad del recurso agua hace posible el desarrollo del mundo rural y el equilibrio territorial, en un momento en el cual los alimentos a bajo precio, en el mercado internacional, se han acabado (crisis alimentaria, emergencia económica de China e India y las graves y prolongadas sequías de los países productores).

La agricultura sostenible no despilfarra agua sino que la usa para producir alimentos de consumo humano aunque es necesario mejorar su eficiencia, el ahorro y su calidad. Las medidas alternativas a la derogación de la ley 10/2001 (Plan Hidrológico Nacional) en junio de 2004 se plasma en el Programa AGUA (Actuaciones para la Gestión y Utilización del Agua). La nueva política se basa en la utilización de la investigación y la innovación tecnológica que permite tanto el ahorro y la eficiencia en el uso del agua como garantizar la disponibilidad y calidad de suministro en cada territorio.

La aplicación del Programa AGUA a la provincia de Alicante permite comprobar el aumento de la oferta de caudales para la agricultura y la disminución 
de uso. Se pasa de utilizar $53 \mathrm{hm}^{3}$ de aguas depuradas en el año 2003 a $70 \mathrm{hm}^{3}$ en el año 2007 y hasta $100 \mathrm{hm}^{3}$ en el año 2010. Un proceso que comporta mejora medioambiental y optimización en la gestión de las aguas. También, el volumen de agua procedente de la desalinización, para uso agrario, contempla pasar de $32 \mathrm{hm}^{3}$ en el año 2004 a $100 \mathrm{hm}^{3}$ en el $2010\left(40 \mathrm{hm}^{3}\right.$ de la desalinizadora de Torrevieja y $20 \mathrm{hm}^{3}$ de la de Guardamar del Segura y el resto de otras ya instaladas), a pesar de su elevado coste para el agricultor, 0,30 euros por metro cúbico. Una tarifa que dista considerablemente de los 0,10 euros por metro cúbico de las aguas del Tajo-Segura. Es la forma de subvencionar a la agricultura productiva y sostenible del Mediterráneo. Nueva asignación de recursos de agua para uso agrario que se implementa con los $80 \mathrm{hm}^{3} /$ año contemplados en el trasvase Júcar-Vinalopó. Aumento de disponibilidad de caudales para uso agrario que se acrecienta por la contribución de la superficie de riego localizado y su eficiencia.

La optimización del riego mediante las técnicas del sistema de goteo o localizado conlleva un ahorro entre el $20 \%$ y $30 \%$ respecto al sistema de riego tradicional o inundación, reducción de costes de producción entre el 28\% y $30 \%$ y mejora de la productividad. Una forma más práctica de producción agrícola que reduce costes por los efectos inducidos derivados de la fertirrigación y el ahorro de mano de obra para obtener mayores cosechas y de más calidad. La aplicación del nuevo sistema de riego localizado a escala de la Comunidad Valenciana confirma que los regantes han ahorrado $340 \mathrm{hm}^{3} \mathrm{du}-$ rante el período 2001-2006. El uso del agua para el sector agrario ha pasado de acaparar el $80 \%$ del consumo regional al 65\%. En el mismo sentido, SEIASA de la Meseta Sur y la Comunidad Valenciana confirma que la modernización de los regadíos de la provincia de Alicante, en el período 2004-2007, afectó a 78000 ha y un ahorro de agua de $75 \mathrm{hm}^{3}$ que contrasta con los $51-53 \mathrm{hm}^{3}$ según otros agraristas. Una actuación sobre el espacio regado que persiste en el tiempo para conseguir el objetivo de establecer el riego localizado en toda la superficie transformada, en el período ya mencionado de 2010-2011.

No se necesita ser un gran conocedor de la problemática hídrica del territorio alicantino para entender que su ordenación hidráulica es una necesidad estructural de la sociedad, fundamental para su modernización agraria, el desarrollo industrial y el abastecimiento urbano, especialmente turístico, en expansión. Los recursos teóricos superficiales y subterráneos renovables se estiman en $590 \mathrm{hm}^{3} /$ año distribuidos desigualmente entre $150 \mathrm{hm}^{3}$ correspondientes a la escorrentía superficial (sólo $15 \mathrm{hm}^{3}$ regulados y aprovechados) y $440 \mathrm{hm}^{3} /$ año a la subterránea (ciclo hídrico). Este escaso potencial del régimen natural es el origen de los problemas de falta de agua como de su 
baja calidad (procedentes del río Segura) cuando el desarrollo agrario necesita recursos de buena calidad (baja conductividad) para el riego de hortalizas, cítricos, arbolado, flores, etc. Un déficit hídrico estructural que condiciona el desarrollo de la actividad agraria necesitado de una solución definitiva.

Esta falta de agua permanente en el sector agrario agobia a la economía rural y explica el abandono de 28018 ha entre 1986-2006. También que el espacio regado cedido al barbecho por el agricultor sea de 15000 ha /año (de las 110104 ha sólo 95506 se cultivan). Un proceso que justifica la deslocalización de la actividad productiva ya que los grandes productores hortofrutícolas de provincia (cosecheros-exportadores) han optado por cultivar en Andalucía, Castilla y León e incluso en Marruecos y Portugal (cuenca del Guadiana) con garantía de agua. La erradicación del déficit hídrico que soporta la agricultura alicantina sólo se puede resolver mediante la acción conjunta de la optimización de los recursos superficiales y subterráneos renovables, los aportes del río Segura, en constante disminución(cambio climático), el volumen asignado por Ley desde la cabecera del río Tajo(gran irregularidad), la máxima utilización de los caudales no convencionales (regeneración, reutilización, desalinización), la modernización total del espacio regado(riego localizado de alta eficiencia) y el trasvase Júcar-Vinalopó. Esta falta de garantía de agua tiene repercusiones económicas, sociales y ecológicas en las explotaciones agrarias, confirmadas estadísticamente en la reducción de la superficie de los cultivos más significativos, en la disminución de la producción los ingresos monetarios percibidos por el agricultor, en el descenso de la mano de obra y en la pérdida ecológica difícil de evaluar (sobreexplotación de acuíferos). También, en la reducción de la cuota de mercado difícil de recuperar.

En el agua, como en cualquier producto, lo que interesa es la relación calidad/ precio/garantía. El problema de la escasez y su impacto sobre el desarrollo económico de la actividad agraria comporta igualar la demanda a la oferta. El poder disponer de agua desalada y tener la oportunidad de mezclarla con recursos superficiales o subterráneos, a un precio competitivo, permite que el regadío pueda seguir contribuyendo y mejorando el valor productivo agrario. Por ello, la tendencia a la globalización y la progresiva apertura de los mercados agrarios requiere mejorar la eficiencia productiva y la competitividad empezando por las explotaciones agrarias ya que el agricultor depende, cada vez más, de los compromisos adquiridos para la venta de su producción y del calibre de los frutos en los mercados. Se trata de encarar el futuro y la incertidumbre que le rodea de forma pragmática para solucionar definitivamente la problemática de la agricultura más productiva y rentable. Este regadío sostenible actual y de futuro es capaz de administrar bien los recursos de agua y 
Cuadro 1. Ingresos, costes y beneficios de cultivos de regadío

\begin{tabular}{|l|c|c|c|c|c|}
\hline \multicolumn{1}{|c|}{ Cultivos } & $\begin{array}{c}\text { Ingresos } \\
€ / \mathrm{ha}\end{array}$ & $\begin{array}{c}\text { Costes } \\
€ / \mathrm{ha}\end{array}$ & $\begin{array}{c}\text { Beneficio } \\
€ / \mathrm{ha}\end{array}$ & $\begin{array}{c}\text { Producción } \\
\mathrm{kg} / \mathrm{m}^{\mathbf{3}}\end{array}$ & $\begin{array}{c}\text { Beneficio } \\
€ / \mathrm{m}^{3}\end{array}$ \\
\hline Alcachofa & 28000 & 19250 & 8750 & 7,3 & 5,8 \\
\hline $\begin{array}{l}\text { Tomate } \\
\text { invernadero }\end{array}$ & 102000 & 45900 & 56100 & 28,1 & 16,8 \\
\hline $\begin{array}{l}\text { Pimiento } \\
\text { invernadero }\end{array}$ & 120000 & 42000 & 78000 & 50,0 & 37,5 \\
\hline Lechuga & 10400 & 6240 & 4160 & 16,0 & 4,4 \\
\hline Naranjo & 10500 & 4935 & 5565 & 8,8 & 2,6 \\
\hline Uva de mesa & 13000 & 9000 & 4000 & 5,7 & 3,7 \\
\hline Flores & 133712 & 95332 & 38380 & - & - \\
\hline $\begin{array}{l}\text { Plantas } \\
\text { ornamentales }\end{array}$ & 48000 & 12000 & 36000 & - & - \\
\hline Melón & 13000 & 10270 & 2730 & 12,6 & 0,9 \\
\hline Níspero & 24000 & 15600 & 8400 & 6,0 & 2,1 \\
\hline
\end{tabular}

Fuentes: Productores y cooperativas locales. Elaboración propia.

obtener un producto agrícola competitivo en calidad y precio, en un mercado cada vez más globalizado.

El beneficio de los cultivos más emblemáticos (cuadro 1) del espacio regado confirma que las hortalizas, el sector de las frutas y la flores y plantas ornamentales tienen considerables posibilidades de poderse expansionar pero condicionadas a las mejoras de competitividad de la producción y la comercialización. La agricultura hortícola alicantina es una actividad paradigmática en el contexto agrícola español por su proyección en el mercado interior y de la UE. El gran despegue se produce en la década de los años setenta aunque pierde importancia cuantitativa y cualitativa en el contexto español y comunitario. La superficie cultivada ha variado de 22730 ha en 1974 a 10442 en el año 2000 y a 10329 en el 2006. La posible ampliación es una oportunidad lógica derivada de las ventajas competitivas que caracterizan al regadío sostenible. Este regadío es rentable y competitivo porque aumenta la producción por superficie cultivada, reduce el coste por hectárea cultivada (sistema de riego), mejora la calidad del producto obtenido y el calibre de los frutos y accede al mercado en función del control del producto y su precio correspondiente. Exportaciones que se concentran en el período octubre-junio con el $86 \%$ de la producción para descender en los meses estivales cuando las condiciones climáticas permiten la llegada al mercado de las producciones de otras zonas de la UE y las procedentes del área de libre comercio. En consecuencia, 


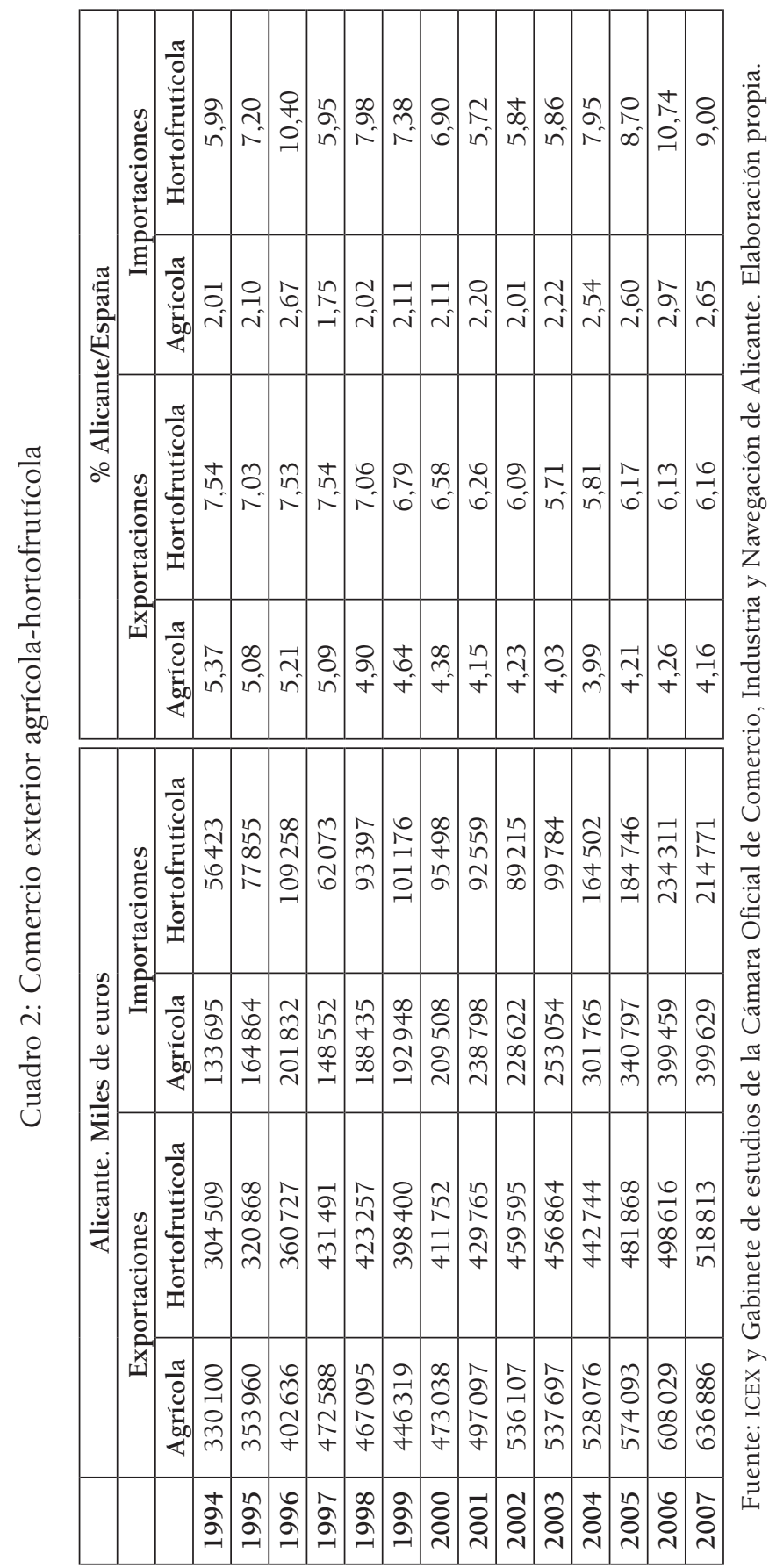

Investigaciones geográficas, n. ${ }^{\circ} 45$ (2008) 
la explotación moderna de cultivos de primor es competitiva respecto a otros aprovechamientos del suelo al conseguir beneficios económicos anuales que superan el precio de venta del terreno para uso urbano (tomates, pimientos, flores, plantas ornamentales, alcachofas, etc.). El incremento de la productividad agraria generada por el regadío, desde el año 2000, ha logrado que una población activa agraria cada vez menor produzca alimentos para atender la demanda de una mayor población urbana en cuanto a variedad, cantidad y calidad de alimentos.

El análisis del comercio agrícola-hortofrutícola de la provincia durante el período 1994-2007 permite valorar su contribución a la economía del sector y a la del conjunto provincial (cuadro 2).La exportación agrícola ha variado de 330 millones de euros en 1994 a 636 millones en el año 2007 (aumenta en el 92,7\%) mientras la hortofrutícola ha pasado de 304 millones a 518 (crece el $70,4 \%)$. Sin embargo, en términos relativos la provincia pierde importancia ya que la exportación agrícola desciende del 5,37\% de 1994 al 4,16\% en el año 2007. Proceso que se hace extensivo a la exportación hortofrutícola al pasar de acaparar, en la relación porcentual Alicante/España, del 7,54\% en la primera de las fechas al 6,16\% en el año 2007. Balance comercial de la producción agrícola de la provincia (exportaciones-importaciones) que sigue siendo positivo frente al correspondiente hortofrutícola (importaciones) que ha pasado del 5,99\% al 9\%, con máximo de 10,7\% en el período de sequía, 2004-2008. Una dinámica necesitada de cambio.

En consecuencia, la clave para elevar la producción agrícola (fortaleza productiva) radica en el aumento de los terrenos regados (hasta $125000 \mathrm{ha}$ ), en una mejor gestión del agua y el suelo en las zonas ya puestas en riego (ceder menos del 5\% de la superficie al barbecho) y en conseguir la mayor eficiencia tanto de los caudales utilizados como de la productividad del campo. El objetivo es producir más alimento con menos agua en condiciones sostenibles. Esto es posible mediante la incorporación al proceso productivo de los avances técnicos de la modernización y la mejor gestión del agua para garantizar el abastecimiento mediante la acción conjunta de los recursos tradicionales y alternativos (aguas residuales y depuradas, plantas desalinizadoras, sondeos y recargas de acuíferos). Enfoque integrado preocupado por los aspectos científicos y técnicos como socioeconómico (contribuir a mejorar la calidad de vida de los agricultores) y durabilidad medioambiental preservada. 
Criterio económico:

- El ahorro de agua varía entre los 51-53 $\mathrm{hm}^{3} / \mathrm{año}$ de respetados investigadores interesados en el tema agrario y los $75 \mathrm{hm}^{3} /$ año de la Sociedad Estatal de Infraestructuras Agrarias (SEIASA).

- Este ahorro es consecuencia del cambio del sistema de riego por inundación al de goteo en una superficie de casi 80000 ha. Una política de actuación sobre el espacio de regadío tendente a su total realización.

- El sector agrario disminuye el consumo de agua y otros sectores lo incrementan (turismo en expansión y aumento de población). La política de regadío eficaz permite que éste sólo consuma el 65\% del total provincial, igual porcentaje que la Comunidad Valenciana, frente al 75\% de España y Europa. Este agua consumida produce el 2\% del PIB y acoge el 3\% de la población activa provincial, respectivamente.

- La mayor eficiencia en la utilización del agua se plasma en la correspondiente disminución de costes de producción, en un $28 \%$, mejorando la competitividad.

- Aumento de la producción de la superficie de regadío entre 10 y 15 veces respecto a la misma superficie de secano, frente a seis veces como valor medio de España.

- Aprovechar el suelo mediante producciones compatibles con la PAC y OMC que permiten su exportación y significarse como el factor principal de supervivencia del agricultor, al facilitar alimentos seguros en cantidad y calidad.

- Mejora el nivel de vida de los agricultores al incrementar la productividad del trabajo y la renta de las explotaciones. Se debe aumentar la dimensión de las explotaciones y el grado de la comercialización para competir más ventajosamente en el mercado cada vez más globalizado (agruparse en cooperativas como: Uva de mesa, Níspero y Surinver, en Pilar de la Horadada, que gestiona la venta de su producción de pimiento de California en EE.UU. y Japón).

- Individualización de la agricultura del sector litoral como el área de privilegio por mayor crecimiento económico y social.

- Los cultivos forzados como tomate, pimiento, flores, son los que producen alta rentabilidad por unidad de superficie y el mayor beneficio por metro cúbico de agua utilizada, incluso con la procedente de la desalinización (de mayor coste, 0,30 euros por metro cúbico). 


\section{Criterio social}

- La nueva ley de Desarrollo sostenible del Medio rural apuesta por introducir mejoras en el sector agrícola como una acción para garantizar el desarrollo rural.

- El regadío del sector litoral genera un empleo directo de hasta 50 veces más que en secano en relación con las orientaciones productivas (cultivos forzados) y el tipo de riego.

- Aumento de la producción de alimentos por mayores rendimientos por unidad de superficie y, si es posible, más de una cosecha. Una forma de contribuir a ordenar los mercados globalizados de los productos agrarios.

- Proporcionar oportunidades económicas a una industria transformadora (diversificación de la actividad productiva) de implantación local y posterior comercialización mejorando la calidad de vida del medio rural.

- Fijar población en las zonas rurales. La población y la densidad en estas zonas regadas ha aumentado en un $15 \%$ y en un 54\%, respectivamente, mientras que a escala nacional lo ha hecho sólo en un $6 \%$ y $8 \%$.

- Adopción de nuevas tecnologías del regadío para el control de los cultivos y paralelo desarrollo de servicios auxiliares.

Criterio ambiental:

- Adecuada gestión de tierras y aguas que eviten su degradación.

- La regeneración y uso de las aguas residuales constituyen un reto y a la vez una oportunidad para ser aplicada en las zonas rurales. Un reto porque el uso de las aguas residuales es la única opción de que disponen los agricultores. También una oportunidad porque estas aguas regeneradas son un recurso valioso tanto desde la perspectiva económica como ambiental.

- La provincia de Alicante es la que mejor gestiona y reutiliza el agua residual en España.

- El medio ambiente se beneficia al introducir las aguas depuradas en el ciclo natural, $72 \mathrm{hm}^{3}$ en el año 2007 y hasta $100 \mathrm{hm}^{3}$ en el año 2010.

- Disminución de los usos del agua por incorporación de mejoras técnicas y mayor producto aparente $\left(€ / \mathrm{m}^{3}\right)$.

- Evitar la contaminación difusa y la sobreexplotación de acuíferos del Vinalopó y de la cuenca del Segura como externalidades más potentes generadas por la agricultura.

- Rentabilidad medioambiental (asentamiento de población). Reducir los procesos de despoblamiento y vertebrar el territorio. 
- Disminución de la presión sobre los recursos hídricos convencionales por las aportaciones procedentes de la desalinización para uso agrario. Hasta $100 \mathrm{hm}^{3}$ /año en el 2010.

- Acción conjunta de la optimización de los diferentes recursos de agua como forma de solucionar el déficit hídrico estructural sin acudir a la sobreexplotación de los caudales subterráneos.

- Por último, hacer más habitable el territorio mediante la protección de sus paisajes creados.

En consecuencia, la agricultura de regadío sostenible de la provincia de Alicante se encuentra inserta en un contexto de economía del agua ya aceptado por la sociedad. Los procesos que conforman su evolución y determinan su futuro tienen como objetivo garantizar el abastecimiento de caudales en cantidad y calidad para no condicionar su desarrollo económico como la incorporación de todos los avances técnicos. La corrección por economía del agua, nuevas aportaciones, regeneración de los caudales urbanos e industriales y su devolución al ciclo natural hídrico como la desalinización (aguas salinas y salobres), la viabilidad de las nuevas tecnologías (mejor gestión y racionalización de los recursos disponibles) y la culminación del trasvase Júcar-Vinalopó permitirán recuperar las ventajas comparativas de la agricultura alicantina en el mercado nacional, de la UE y el globalizado. Una de las zonas con mayor potencial agrícola del área mediterránea con posibilidades de expansión en hortalizas, cultivos leñosos, flores (la UE importa el 90\%) y plantas ornamentales pero condicionada a las mejoras de la competitividad de la calidad del producto, las condiciones sanitarias y su comercialización mediante cooperativas para levantar el sector y afrontar el futuro. Es la mejor forma de superar la crisis de rentabilidad que soporta el campo para que el agricultor pueda vivir dignamente, ofrecer productos saludables y de calidad para el consumidor y respeto al medio ambiente.

\section{Conclusiones}

1. La única agricultura sostenible en la provincia de Alicante es la de regadío necesitada de garantía de suministro de agua en cantidad y calidad.

2. Esta forma de explotación de la tierra reúne una serie de condiciones objetivas y ventajosas para mantener la función de producción agrícola en el mercado de la Unión Europea y globalizado. Es sostenible, rentable, exportadora, generadora de empleo y goza de una favorable renta de situación. Agricultura de vanguardia que es motor de desarrollo económico y social en un tiempo en el cual se aboga por un equilibrio de los 
sectores productivos frente a la dependencia del monocultivo industrial o turístico.

3. La insuficiencia e inseguridad de caudales para uso agrario repercuten negativamente en la economía de la provincia tanto por el valor de su producción como por la capacidad de trabajo y la actividad exportadora que pierde importancia en relación con España. Se ha pasado de acaparar el 5,37\% de la exportación agrícola total en 1994 y el 7,54\% del sector hortofrutícola a 4,16\% y 6,16\%, respectivamente, en el año 2007. Una tendencia necesitada de un cambio radical en su dinámica.

4. La escasez de agua y su calidad deben dejar de ser un problema para el desarrollo sostenible del regadío de la provincia. La agricultura de regadío sostenible de la provincia tiene como objetivo que se le garanticen sus necesidades de agua y conseguir una mayor eficiencia en su utilización. La dependencia del agua no debe condicionar el futuro de la competencia de otros usos alternativos (turismo) y los cambios en el mercado internacional de intercambios comerciales.

5. La falta de agua en el territorio alicantino no tiene una solución única. La erradicación del déficit hídrico que soporta la agricultura sólo se puede resolver mediante la acción conjunta de la optimización de los recursos superficiales y subterráneos renovables, los aportes del río Segura, el volumen de agua asignado por ley desde la cabecera del río Tajo, la máxima utilización de caudales no convencionales (depuración, reutilización y desalación), la modernización total del espacio regado (alta eficiencia) y el trasvase Júcar-Vinalopó. En el agua, como en cualquier producto, lo que interesa es la relación calidad/precio/garantía.

6. La necesidad de agua para riego debe garantizarse aunque el precio pueda ser más caro por la desalinización del agua del mar y las salobres. Su empleo es rentable en la zona de influencia de la costa(cultivos hidropónicos de tomate, pimiento, flores, plantas ornamentales) de alto rendimiento por metro cuadrado, producción intensiva y elevado valor añadido. La sostenibilidad contempla al agua como factor de producción mientras permite combinar los diferentes recursos para que su utilidad sea máxima y perdurable a lo largo del tiempo.

7. La sociedad, los técnicos y los políticos en su conjunto deben resolver favorablemente las necesidades de riqueza y bienestar para las generaciones actuales, logrando la plena satisfacción de disponibilidad hídrica sin afectar a la demanda futura. 


\section{Bibliografía}

CÁmara oficial de Comercio, Industria y NaVegación De Alicante.

CANALES, G. y C. JuÁREZ (1994): Nuevos regadíos en el secano del Bajo Segura: el modelo referencial de San Onofre-Torremendo (1953-1992) en Investigaciones Geográficas, n. ${ }^{\circ}$ 12, pp. 215- 237.

GIL, A. y A. M. Rico (2007): El problema del agua en la Comunidad Valenciana, Fundación de la Comunidad Valenciana Agua y Progreso, Valencia, 221 pp.

JuÁreZ, C. (1988): «Mejoras técnicas en el regadío alicantino: disminución del consumo y aumento de la productividad», en Demanda y Economía del Agua en España, Alicante, Instituto de Estudios Juan Gil-Albert, CAM, Instituto Universitario de Geografía, pp. 389-402.

- (1989): «Recursos y usos del agua en las comarcas de Alicante» en R. MARTín, et al.: El reto del agua, Diputación Provincial de Alicante, pp. 7-103.

- (1991): Planificación hidrológica y desarrollo económico: El trasvase Tajo-Segura, Instituto de Cultura Juan Gil-Albert, Alicante, 167 pp.

- A. RAmón, G. Ponce y G. CAnales (1993): «Las agriculturas alicantinas» en A. Pedreño: Estructura económica de la provincia de Alicante, Diputación Provincial de Alicante, pp. 147-171.

- (1996): Aumento de recursos de agua: nuevas tecnologías y repercusión socioeconómica en la Vega Baja y el Bajo Vinalopó» en Investigaciones Geográficas, n. ${ }^{\circ} 15$, pp. 61-77.

- (2000): «El papel de la oferta de agua en el desarrollo productivo de la Vega Baja del Segura (Alicante)», Alquibla, nº 6, pp. 99-118.

- (2004): Asignación de recursos de agua para uso agrario y crecimiento económico en la comarca meridional agraria de Alicante en Estudios Agrosociales y Pesqueros, n. ${ }^{\circ}$ 202, pp. 135-166.

- (2006): «Escasez de agua y transformación económica del sistema territorial de Aspe: retos y oportunidades» en A. ESTÉVEZ et al.: El acuífero cuaternario de Aspe: Contexto socioeconómico, hidrológico y medioambiental, Publicaciones de la Universidad de Alicante, Alicante, pp. 21-69.

- (2008): «Sustainable irrigation in areas with an arid and semi-arid climate in the province of Alicante» en Y. Villacampa, C.A. Brebbia y D. Prats Rico (eds.): Sustainable Irrigation. Management, Technologies and Policies II, Southampton, Wit Press, pp. 223-233.

MARCO, J.B. (1995): «El agua como factor de estrangulamiento de la economía de las Comunidades Valenciana y Murciana» en Ciudad y Territorio. Estudios Territoriales, n. ${ }^{\circ} 105$, pp. 577-588.

Melgarejo, P. y J.J. Martínez (2008): «Influencia económica del Trasvase TajoSegura en la agricultura de la provincia de Alicante», texto mecanografiado, 22 pp. 
RiCO, A.M. (1994): Sobreexplotación de aguas subterráneas y cambios agrarios en el Alto y Medio Vinalopó, Secretariado de Publicaciones de la Universidad de Alicante, Alicante, $276 \mathrm{pp}$.

- (1998): Agua y desarrollo en la Comunidad Valenciana, Universidad de Alicante, Alicante, $163 \mathrm{pp}$.

- (2006): «Políticas agrarias, eficiencia socioeconómica y retos de futuro en los regadíos intensivos», Boletín de la A.G.E., n. ${ }^{\circ} 41$, pp. 113-149.

SAnto, J. (2007): Historia de la Sociedad del Canal de la Huerta de Alicante (19072007), Alicante, Diputación de Alicante, 286 pp.

SEGRELLES, J.A. (1994): «Los problemas del sector agrario alicantino y propuestas de desarrollo», Investigaciones Geográficas, n. ${ }^{\circ} 12$, pp. 239-245. 